\title{
VISUALIZATION AND MODELLING OF THE POLARIZATION LAYER AND A REVERSIBLE ADSORPTION PROCESS IN PEG-10000 DEAD-END ULTRAFILTRATION
}

J. Fernández-Sempere, F. Ruiz-Beviá*, P. García-Algado, R. Salcedo-Díaz.

Departamento de Ingeniería Química. Universidad de Alicante. Apartado 99. E-03080 Alicante (Spain). Fax. +34965903826. Telf. +34965903547. ruiz.bevia@ua.es.

\section{Introduction}

Ultrafiltration (UF) is a pressure-driven process using a semi-permeable membrane to separate macromolecules or colloids from liquids. It is based on a simple sieving mechanism and is a process widely used in the food industry, for effluent treatment, biotechnology and medical applications. The main problem of UF is the important accumulation of solute on the membrane surface, that results in a substantial reduction of the permeate flux. This solute accumulation, according to Van den Berg and Smolders [1], can occur in two ways: i) concentration polarization (i.e. accumulation of retained solutes, reversible and occurring immediately) and ii) fouling phenomena such as adsorption, pore-blocking and deposition of solidified solutes, a longterm and more or less irreversible process. The result of both phenomena is a decreasing driving force for the filtration or an increasing resistance against transport of the permeating solvent during the filtration.

In a relatively recent article of 2001, Sablani et al. [2] critically review a large number of papers related to various aspects (experimental studies, semi-empirical modelling and theoretical studies) of the concentration polarization in UF and reverse osmosis (RO). Protein transport and polarization through membranes using pulsed sample injection technique was studied by Ghosh and Cui [3]. In more recent papers, Chong et al. [4] use a sodium chloride tracer response technique to determine the effect of fouling on the concentration polarization level in a RO 
system, whereas Lyster and Cohen [5] carried out a numerical study of concentration polarization in a rectangular RO membrane channel. Recent papers on UF try to predict, by means of more or less complicated models, the reduction on the permeate flux in ultrafiltration of polyethylene glycol (PEG) [6-7], dextran [8] and bovine serum albumin (BSA) [9]. These models apply different mechanisms to explain the solute accumulation on the membrane. In general, they can been subdivided into (A) resistance models, (B) gel-polarization models and (C) osmotic pressure models or combinations of any of these. This great variety of proposed models has its origin in the difficulties to obtain experimentally and understand accurately the phenomena occurring on the membrane surface and, therefore, the mechanisms conditioning the flux decline.

An important issue in ultrafiltration is knowledge of the characteristics of the fouling phenomenon, which is sometimes irreversible and sometimes reversible. Bachin et al. [10] proposed a unifying model for concentration polarization, gel layer formation and particle deposition in cross-flow membrane filtration of colloidal suspensions. In their conclusions, the authors state a distinction between two possible mechanisms for the formation of irreversible layers: a) the gelation mechanism, i.e. formation of a loose layer with a low fractal dimension, appearing simultaneously across the membrane surface, b) the deposition mechanism, i.e. formation of a compact ordered deposit growing progressively from the outlet to the inlet of the membrane device. There is also experimental evidence of irreversible formation of layers in the case of ultrafiltration of protein solutions [11]. Thus, it is known that in the ultrafiltration of aqueous solutions of BSA, in order to recover the flow of water through the membrane after an experiment, a thorough washing of the membrane is required, even with detergents, in order to eliminate the gel irreversibly deposited.

However Churaev et al. [12], in a recent study about dead-end ultrafiltración of PEG of different molecular weights, found that experimental data were reproducible and most importantly were reversible. The latter indicated the absence of any irreversible gel formation or 
membrane fouling by the PEG molecules. The reversibility of PEG adsorption was also confirmed by the coincidence of the water filtration rates through the membrane, both prior to and after the experiments with PEG. Karode [13], in a study about the nature of the solute and gel layer in membrane ultrafiltration, considers that Dextran T70 does not form a gel at normal UF transmembrane pressures. According to this study, when Dextran T70 is ultrafiltered, a step increase/decrease in transmembrane pressure results in a corresponding reversible increase/decrease in the steady state permeated flux.

In dead-end ultrafiltration, models can theoretically predict the evolution with time of the solute concentration profiles in the vicinity of the membrane surface ([1], [14-15]). Unfortunately, they are not usually accompanied by a comparison with experimental results which could be used to validate the model. The little knowledge about the polarized layer is mainly due to the experimental difficulties associated with making concentration profile determinations within a very thin layer. Chen et al. [16] made a review of non-invasive experimental methods for the observation in-situ and in real-time of membrane processes, providing examples of their use and limitations for liquid-based membrane processes. The paper describes a wide range of optical and non-optical techniques. For instance, nuclear magnetic resonance (NMR) micro-imaging has been used to investigate concentration polarization phenomena in membrane microfiltration of colloidal silica suspensions [17]. On the other hand, interferometry is an optical technique which has been used by several authors [18-21] to visualize the concentration polarization layer.

In previous papers, the holographic interferometry technique was used to visualize the appearance, evolution with time and disappearance of the concentration polarization layer during ultrafiltration of BSA and PEG-2000 solutions [22-23], as well as reverse osmosis (RO) of salts [24-26]. This technique, which has also been used to study diffusion processes, [27-28] allows interferometric fringes patterns to be obtained, that are indicative of changes in the optical path followed by the light and are related to changes in the refractive index. In the case of the 
appearance of the concentration polarization layer during the ultrafiltration process, changes in the concentration distribution, and therefore in the refractive index distribution, can be visualized as an interference fringe pattern.

In the present paper, holographic interferometry was used to visualize the evolution of the concentration profiles during the ultrafiltration process of PEG-10000 solutions with different concentrations in an unstirred cell. From the experimental results, evidence was found about the existence of an adsorption of solute on the membrane surface. This adsorption process is considered to be reversible because, when the driving force ceases, holographic interferometry allows us to view in real-time that the solute accumulated on the membrane returns to solution.

Solute accumulation on the membrane, i.e. adsorpted, has been modelled using an empirical equation. This equation has been solved along with the global transport equations of convectiondiffusion for the UF process using a combination of two models: the osmotic pressure and the hydraulic resistance due to the adsorption layer. The experimental permeate flux and the experimental concentration profiles were in good agreement with those predicted by the model.

\section{Theory}

Assuming a convection-diffusion mechanism, the unsteady-state mass balance in the polarization layer is:

$$
\frac{\partial \mathrm{C}}{\partial \mathrm{t}}=\mathrm{J} \frac{\partial \mathrm{C}}{\partial \mathrm{y}}+\frac{\partial}{\partial \mathrm{y}}\left(\mathrm{D} \frac{\partial \mathrm{C}}{\partial \mathrm{y}}\right)
$$

where - $\mathrm{C}$ is the concentration of solute $\left(\mathrm{kg} / \mathrm{m}^{3}\right)$, which depends on $\mathrm{t}$ and $\mathrm{y}$

- $\mathrm{t}$ is the time (s)

- $\mathbf{J}$ is the average volumetric permeate flux $\left[\mathrm{m}^{3} /\left(\mathrm{m}^{2} \mathrm{~s}\right)\right]$

- $\mathrm{y}$ is the distance $(\mathrm{m})$ on the boundary layer 
- D is the diffusion coefficient $\left(\mathrm{m}^{2} / \mathrm{s}\right)$, assumed to be concentration independent with the following boundary conditions (Figure 1).

$$
\begin{array}{lll}
\text { at } \mathrm{t}=0 & \mathrm{C}=\mathrm{Co} & \forall \mathrm{y} \\
\text { at } \mathrm{y}>\delta & \mathrm{C}=\mathrm{Co} & \forall \mathrm{t}
\end{array}
$$

where $\delta$ is the polarization layer thickness

The boundary condition applied on the membrane surface is:

$$
\text { at } \mathrm{t}>0 \text { and } \mathrm{y}=0 \quad \mathrm{JC}_{\mathrm{m}}+\mathrm{D}\left(\frac{\mathrm{dC}}{\mathrm{dy}}\right)_{\mathrm{y}=0}=\mathrm{JC}_{\mathrm{p}}
$$

$\mathrm{C}_{\mathrm{m}}$ is the solute concentration at the membrane surface and $\mathrm{C}_{\mathrm{p}}$ is the solute concentration in the permeate flux.

In the case of PEG-10000 ultrafiltration, a solute adsorption or deposition on the surface of the membrane can occur. Therefore, a term that takes into account the accumulation of solute must be added to the boundary condition (4). So, if a perfect selective membrane $\left(C_{p}=0\right)$ is assumed, equation (4) becomes:

$$
\text { at } t>0 \text { and } y=0 \quad \mathrm{JC}_{\mathrm{m}}+\mathrm{D}\left(\frac{\mathrm{dC}}{\mathrm{dy}}\right)_{\mathrm{y}=0}=\frac{\mathrm{dS}}{\mathrm{dt}}
$$

where $S_{a}$ is the amount of solute adsorbed or deposited on the surface of the membrane, in $\mathrm{kg} / \mathrm{m}^{2}$.

In a dead-end ultrafiltration process, the convection-diffusion equation (5) assuming a convection-diffusion mechanism, is usually combined with the osmotic pressure model (6):

$$
\mathrm{J}=\frac{\Delta \mathrm{P}-\Delta \pi}{\mathrm{R}_{\mathrm{m}}}
$$

where $\Delta \mathrm{P}$ is the pressure applied, $\Delta \pi$ is the osmotic pressure difference across the membrane $\left[\pi\left(C_{m}\right)-\pi\left(C_{p}\right)\right]$ and $R_{m}$ is the membrane hydraulic resistance to the flux with pure water $\left(J_{w}\right)$, which is calculated as:

$$
\mathrm{R}_{\mathrm{m}}=\frac{\Delta \mathrm{P}}{\mathrm{J}_{\mathrm{w}}}
$$


Once the ultrafiltration process begins, other resistances appear and new terms must be added in equation (6). In this paper, it has been considered that a certain amount of solute was absorbed on the membrane surface. As a consequence, a new resistance $\left(R_{a}\right)$ has been included in equation (6) to take this adsorption into account [29].

$$
\mathrm{J}=\frac{\Delta \mathrm{P}-\Delta \pi}{\mathrm{R}_{\mathrm{m}}+\mathrm{R}_{\mathrm{a}}}
$$

\section{Experimental}

\subsection{Experimental set-up}

The experimental assembly was made up of an optical system (holographic interferometry) and an ultrafiltration system, coupled on the same work table. The common element to both systems was the UF cell, specially designed to carry out the ultrafiltration process satisfying the holographic interferometry requirements.

The optical set-up (Figure 2) was similar to that described in a previous paper [26]. An optical rail was added to this system to easily carry the focusing lens. This optical rail allowed refocusing the object, thus changing the magnification and enlarging or reducing the area observed in order to obtain a better monitoring of the evolution of the polarization layer.

The UF set-up (Figure 3) was similar to the reverse osmosis set-up described in a previous paper [26]. The ultrafiltration cell, provided with two windows thus allowing the membrane surface to be visualized, was horizontally placed on the optical table (Figure 3) with the membrane surface facing upward $\left(0^{\circ}\right)$. It should be noted that in previous papers on UF with solutions of BSA [22] and PEG [23], the UF module was placed in a different orientation (vertical position, $\left.90^{\circ}\right)$. Placing the module in horizontal position $\left(0^{\circ}\right)$, as in the present paper, avoids the appearance of gravitational instabilities or buoyancy effects that often occur when the 
membrane surface has a vertical $\left(90^{\circ}\right)$ or a horizontal facing downward $\left(180^{\circ}\right)$ orientation. These buoyancy effects have been previously reported in UF [30] and RO [25]. The ultrafiltration cell used is the same as that used in reverse osmosis, which was thoroughly described in a previous paper [31]. The active membrane dimensions were $10 \times 1 \mathrm{~cm}$ with a $10 \mathrm{~cm}^{2}$ effective area, a size chosen to satisfy the interferometric requirements. The distance from the membrane surface to the top of the cell was $40 \mathrm{~mm}$, so the volume of solution in the cell was large enough to guarantee that concentration changes inside the cell would only take place near the membrane. Therefore, far from the membrane surface, the bulk concentration $\left(\mathrm{C}_{\mathrm{o}}\right)$ will remain unchanged during the process.

\subsection{Materials}

A cellulose acetate membrane, YC05 from Millipore with nominal molecular weight limit (NMWL) 500, was used. Suitable pieces for the size of the cell used were cut from the whole membrane. As each piece of membrane was used for several runs, after each experiment the membrane was washed, in cross-flow, with water flowing through the UF module until the solute was completely removed from the membrane surface. The membrane was considered to be clean when the permeate flux of water was recovered.

In order to study the effect of the feed concentration on the polarization layer, the experiments were carried out using solutions of PEG-10000 (Sigma) with different initial concentration $\left(\mathrm{C}_{\mathrm{o}}\right)$, in the range from 5 to $12.5 \mathrm{~kg} / \mathrm{m}^{3}$.

The diffusion coefficient of the PEG-10000 solutions used $\left(0.0826 \cdot 10^{-9} \mathrm{~m}^{2} / \mathrm{s}\right)$ was obtained from literature [32]. The osmotic pressure was calculated with equation:

$$
\Pi(\mathrm{MPa})=379.3 \mathrm{M}^{2}-37.9 \mathrm{M}
$$

where $\mathrm{M}$ is the molarity of the solution [33]. 


\subsection{Experimental methodology}

The experimental method was similar to that explained in previous papers [22-24].

Three runs of ultrafiltration experiments of PEG-10000 were carried out using four different feed concentrations $\left(5,7.5,10\right.$ and $\left.12.5 \mathrm{~kg} / \mathrm{m}^{3}\right)$. All the experiments were performed in batch conditions using a constant pressure of 1 bar. Prior to each experiment the water flux $\left(\mathrm{J}_{\mathrm{w}}\right)$ was measured, giving an average value of $2 \times 10^{-6} \mathrm{~m}^{3} /\left(\mathrm{m}^{2} \mathrm{~s}\right)$.

Once it was checked that the pure water permeate flux was correct, the ultrafiltration system was filled with the PEG solution. After a few seconds, with the solution at rest, the cell was aligned with the optical system and the hologram was recorded. This state with the solution at rest was used as the reference state of the process. With the hologram developed, constant pressure of 1 bar was applied. A convective flux of solute to the membrane surface began, thus causing the accumulation of the solute in the vicinity of the membrane. Concentration on the membrane surface $\left(\mathrm{C}_{\mathrm{m}}\right)$ increased and so did the refraction index, causing the appearance of interference fringes when comparing the actual state and the reference state (the hologram).

Each interference fringe corresponds to a concentration step in the solution. This step depends on the relation between the concentration and the refraction index, measured at $25^{\circ} \mathrm{C}$ with a refractometer (Leica, AR600).

$$
\mathrm{n}=0.000132 \cdot \mathrm{C}\left(\mathrm{kg} / \mathrm{m}^{3}\right)+1.33299
$$

Methodology to obtain the concentration from the interferograms was described in previous papers $[22,24]$. The interferograms, at a rate of 24 per second, were captured with a video camera and recorded with video capture software in a PC.

During all the experiment, data of the evolution of the permeate weight were taken to calculate the permeate flux. Several samples, depending on the amount of permeate, were taken to measure their refraction index and calculate the concentration of permeate. In all of the experiments the concentration of the permeate solution was nearly 0 indicating almost complete 
rejection of the solute. This result was expected due to the high difference between the nominal molecular weight limit (NMWL) of the membrane (500) and the molecular weight of the solute (10000).

After one hour of experiment, pressure was removed and the convective flux of solute ceased. Interference fringes should disappear but, during the first twenty minutes approximately, the number of interference fringes increased. This effect will be explained later.

\section{Results and Discussion}

\subsection{Visualization of the polarized layer}

Holographic interferometry allows an in-situ real-time visualization of the evolution of the appearance and disappearance of the polarization layer during a dead-end ultrafiltration experiment. Several ultrafiltration experiments of PEG-10000 were carried out for each feed concentration used $\left(5,7.5,10\right.$ and $\left.12.5 \mathrm{~kg} / \mathrm{m}^{3}\right)$. Once the pressure was applied and the process began, the appearance of some fringes near to the membrane was observed. As the process went on, fringes got wider and moved away from the membrane; at the same time, new narrow fringes continued appearing near the membrane surface. This behaviour indicated that concentration on the membrane $\left(\mathrm{C}_{\mathrm{m}}\right)$ and the polarization layer thickness $(\delta)$ grew with time.

Interferograms at 15, 30, 45 and 60 minutes, corresponding to two experiments with the same transmembrane pressure $(\Delta \mathrm{P}=1$ bar $)$ and different initial concentration of PEG-10000 (7.5 $\mathrm{kg} / \mathrm{m}^{3}$ and $12.5 \mathrm{~kg} / \mathrm{m}^{3}$ ), are shown in Figures 4 and 5 . As each experiment was recorded in a continuous way, a great number of interferograms were available. Interferograms in these figures have been selected, as an example, to illustrate the evolution of the system. In each 
interferogram, a horizontal line and an auxiliary scale have been drawn in order to show where the membrane surface initially was as well as the magnification used in the experiment.

The behaviour in both experiments was very similar. As can be observed in Figures 4 and 5 the number of fringes and their distance from the membrane surface increases when the time increases. The appearance of new interference fringes, as well as the growth of the boundary layer, takes place during all the experiment. In Figure 4, at 30 minutes there were 9 fringes and $\delta$ $=0.45 \mathrm{~mm}$ approximately. At 60 minutes the number of fringes have doubled up to 18 fringes and $\delta=0.85 \mathrm{~mm}$. This continuous growth in $\mathrm{C}_{\mathrm{m}}$ and the boundary layer indicates that the process is quite far from the stationary state.

Video 1 (http://www.ua.es/es/servicios/si/servicios/videostreaming/iq/UF_PEG_video1.html) shows an experiment (60 minutes) with initial concentration of PEG-10000 $=12.5 \mathrm{~kg} / \mathrm{m}^{3}$. The velocity in the video has been increased 60 times, so the video is 1 minute long.

The behaviour in these UF experiments contrasts with that observed when RO experiments were carried out [24]. In RO, at the beginning of the experiment, the number of fringes (and therefore, $\mathrm{C}_{\mathrm{m}}$ ) increased very quickly, later increasing much more slowly. However, in UF, the increase in the number of fringes was slower and more regular, and the value of $\mathrm{C}_{\mathrm{m}}$ was lower than in RO experiments. Another difference was that whereas in RO the amount of solute retained by the membrane (the area under the curve concentration-distance) was very similar to the total mass of solute that has entered in the boundary layer by convection during the filtration period, in UF the amount of incoming solute was greater than the solute retained. These experimental results indicate that the mechanisms that explain the phenomena occurring on the surface of the membrane in UF are different from those taking place in RO. This will be confirmed later when commenting on the experimental results that are obtained when the pressure (and hence, the convective transport of solute to the surface of the membrane) ceases.

Once pressure ceased, the evolution of interference fringes also showed a singular behaviour, quite different from that observed in the experiments of $\mathrm{RO}[24,26]$. 
In RO the fringes became wider and slowly disappeared, thus indicating a decrease in the concentration on the membrane surface as well as a slightly increase in the boundary layer thickness. It was a consequence of the diffusive movement of the solute accumulated in the polarization boundary layer during the process, from the solution closest to the membrane surface to the bulk solution, the driving force being the difference of concentration between both solutions.

However, in the ultrafiltration of PEG-10000, once the pressure ceased, a fast appearance of new fringes during the first minutes was observed, which means that $\mathrm{C}_{\mathrm{m}}$ quickly increased. The rate of appearance of fringes slowed down as the experiment continued and, after a few minutes, this number reached a maximum and started to decrease, the final step of the process thus being similar to that found in RO experiments. At the same time, the boundary layer thickness was increasing continuously (only slightly in the first few moments, and more after some minutes).

Figures 6 and 7 show several interferograms (at 0, 5, 12, 25, 35 and 50 minutes after the pressure ceased) corresponding to the experiments previously cited $\left(7.5\right.$ and $\left.12.5 \mathrm{~kg} / \mathrm{m}^{3}\right)$. In these Figures, interferograms at 0 minutes correspond to interferograms at 60 minutes in Figures 4 and 5, just before the driving force ceased. In Figures 6 and 7, the almost immediate appearance of a high number of fringes can be observed. For example, in Figure 6 there are 31 fringes at 5 minutes after the pressure ceased, nearly twice as there were at 60 minutes.

Video 2 (http://www.ua.es/es/servicios/si/servicios/videostreaming/iq/UF_PEG_video2.html) shows the evolution of the interference fringes when the pressure ceases. This corresponds to the same experiment as video 1 , with initial concentration of PEG-10000 $=12.5 \mathrm{~kg} / \mathrm{m}^{3}$. The last 7 minutes of the UF process $(\Delta \mathrm{P}=1$ bar) can be seen, then the pressure ceases and 13 minutes without pressure $(\Delta \mathrm{P}=0)$ can be seen. The velocity in the video has been increased 20 times, so the video is 1 minute long.

This behaviour can be the consequence of the combination of two phenomena: the process of desorption and the diffusion of solute back to the solution. During the first few minutes, the 
predominant mechanism was desorption of the solute layer on the membrane surface. As time goes by, the solute provided from the membrane became lesser than the solute that went back to the bulk solution by diffusion and the number of interference fringes decreased. In Figure 6 (at $12,25,35$ and 50 minutes after the pressure was ceased) the number of fringes is $43,41,37$ and 32, respectively. The return of the solute adsorbed on the membrane towards the bulk solution shows that this adsorption process was physical and reversible. Finally, the interference fringes became wider and the thickness of the boundary layer increased, the fringes disappearing with time as the diffusion progressed and incorporating the solute in the bulk solution.

\subsection{Concentration profiles}

Interference fringe patterns from Figures 4 and 5 can be converted into their corresponding concentration profiles by means of the method described in previous papers $[22,24]$. Due to the direct relationship between the refraction index of the solution and its concentration, concentration changes in the polarization layer are also changes in the refraction index. These changes can be visualized as an interference fringe pattern.

Tables 1 to 4 show the evolution of the number of fringes and their position for one experiment of each concentration. Data from Figures 4 and 5 are shown in Tables 2 and 4, respectively.

In Figure 8, concentration profiles at 15, 30, 45 and 60 minutes are shown for the 4 different concentrations used of PEG-10000 $\left(5,7.5,10\right.$ and $\left.12.5 \mathrm{~kg} / \mathrm{m}^{3}\right)$. It can be observed that the concentration in the membrane is continuous and regularly increased. Furthermore, the higher the feed concentration, the greater the difference was between $C_{m}$ and $C_{o}$. At 60 minutes, when $C_{0}=7.5 \mathrm{~kg} / \mathrm{m}^{3}$, the difference between $C_{m}$ and $C_{o}$ was $10 \mathrm{~kg} / \mathrm{m}^{3}$ whereas it was $15 \mathrm{~kg} / \mathrm{m}^{3}$ when $\mathrm{C}_{0}=12.5 \mathrm{~kg} / \mathrm{m}^{3}$. This fact shows that the higher the feed concentration, the higher the slope of the concentration profile. 
The thickness of the boundary layer, however, increased in a slower way and was almost the same after a certain period of time, independently of the feed concentration used. In all the experiments, at 60 minutes, just before the pressure ceased, $\delta$ was slightly higher than $0.80 \mathrm{~mm}$.

The amount of solute $\left(\mathrm{kg} / \mathrm{m}^{2}\right)$ retained by the membrane which still remained in solution in a layer of " $\delta$ " thickness $\left(\int_{0}^{\delta} \mathrm{C} \cdot \mathrm{dy}\right)$ can be obtained from the concentration profile in the boundary layer. The total mass of solute per unit of area that has entered into the membrane by convection during the filtration period $(\mathrm{t})$ can be obtained from the experimental data of permeate flow $(\mathrm{J})$ (see section 4.3) by means of the integral $\int_{0}^{\mathrm{t}}\left(\mathrm{JC}_{\mathrm{o}}\right) \mathrm{dt}$. If there is no solute passing through the membrane (total retention), the mass balance on the control volume specified in Figure 9 would be:

$$
\mathrm{S}_{\mathrm{a}}+\int_{0}^{\delta} \mathrm{C} \cdot \mathrm{dy}=\int_{0}^{\mathrm{t}}\left(\mathrm{JC}_{\mathrm{o}}\right) \mathrm{dt}
$$

where $S_{a}$ is the amount of solute adsorbed per unit of area during the time (t) that lasts the UF process. Previous to the beginning of the UF process (time $\mathrm{t}=0$ and transmembrane pressure $\Delta \mathrm{P}$ $=0)$, the membrane is in contact with the solution of PEG 10000 with initial concentration $\mathrm{C}_{\mathrm{o}}$ and a certain amount of solute $\left(S_{a, o}\right)$ (usually very small) will be adsorbed on the membrane. The total amount adsorbed on the membrane $\left(\mathrm{S}_{\mathrm{a}, \mathrm{t}}\right)$ is:

$$
\mathrm{S}_{\mathrm{a}, \mathrm{t}}=\mathrm{S}_{\mathrm{a}, \mathrm{o}}+\mathrm{S}_{\mathrm{a}}
$$

However, the amount to be included in the mass balance on the volume-control must be $S_{a}$, the amount of solute that has been adsorbed or deposited on the surface of the membrane since $t=0$ (the beginning of the UF process) as a consequence of the convective flow $\left(\mathrm{JC}_{\mathrm{o}}\right)$ with a transmembrane pressure $\Delta \mathrm{P}=1$ bar.

If there is no any build-up of a gel layer or solute adsorption on the surface of the membrane, equation (11) becomes: 


$$
\int_{0}^{\delta} \mathrm{C} \cdot \mathrm{dy}=\int_{0}^{\mathrm{t}}\left(\mathrm{JC}_{\mathrm{o}}\right) \mathrm{dt}
$$

which is fulfilled virtually in the RO experiments as can be checked using the experimental data published in [24]. However, in the UF experiments with PEG-10000, equation (13) was not fulfilled: the amount of incoming solute was greater than the mass of solute in solution accumulated in the boundary layer. This fact indicates that there was an amount of solute retained on the membrane surface but not in the boundary layer, that is to say, this difference of solute must have been adsorpted.

Table 5 shows the amount of solute retained in the boundary layer and the amount that entered into the layer, for the interferograms of Figures 4 and 5 . The difference between both values was significant and gives a measure of the solute adsorpted on the surface of the membrane, thus indicating that the phenomenon of adsorption of PEG during the ultrafiltration process was very important.

Figure 10 shows the experimental concentration profiles at $0,5,12,25$ and 50 minutes after the pressure was ceased, for every feed concentration used (the profile for 0 minutes is the same as that corresponding to 60 minutes of experiment, just prior to ceasing the pressure). It is possible to observe that, as has been explained in section 4.1, the profile undergoes a considerable growth $\left(\mathrm{C}_{\mathrm{m}}\right.$ increases $)$ in the first few minutes, and decreases gradually as the experiment continues.

The appearance of a larger number of fringes after the pressure ceased confirms that there was an amount of solute adsorpted on the membrane surface: once the driving force stops, solute adsorpted returned to the bulk solution, causing an increase of $\mathrm{C}_{\mathrm{m}}$ and the appearance of new fringes near the membrane. When calculating the amount of solute accumulated in the boundary layer $\left(\int_{0}^{\delta} \mathrm{C} \cdot \mathrm{dy}\right)$, the value obtained is greater than that calculated before ceasing the pressure, as a consequence of the desorpted solute which was incorporating into the boundary layer. 
Table 5 also shows the evolution with time of the amount of solute in the boundary layer, once the pressure ceases. The amount of solute increases until a maximum that is close to, but does not equal, the total amount of solute that has been transported by convection to the surface of the membrane during the UF process. Two reasons could explain this inequality: The first one was that a diffusion process was simultaneously taking place with the process of desorption and part of the solute returned to the bulk solution beyond the boundary layer of thickness " $\delta$ ", thus not appearing as fringes in the boundary layer. The other was the small residual amount of solute that remained adsorpted. Nevertheless, this adsorption can also be considered reversible because it can easily be desorpted by rinsing the membrane with pure water and without using any chemical cleaning.

\subsection{Permeate flux}

Throughout the experiment, the evolution with time of the permeate weight was continuously measured and registered to calculate the permeate flux (as the derivative of the curve of weight). Also, in each experiment, several samples of permeate (depending on the amount of permeate collected) were taken to measure their concentration. As previously stated, an almost complete rejection of the solute was assumed.

Figure 11 shows the evolution of the dimensionless permeate flux for each feed concentration used. It can be seen that the permeate flow decreased during all the experiment for each feed concentration. This phenomenon was due, firstly, to the appearance of the polarization layer, which made the concentration on the membrane higher. This high value of $\mathrm{C}_{\mathrm{m}}$ increases the osmotic pressure and, therefore, the effective driving force $\Delta \mathrm{P}-\Delta \pi$ decreases (equation 8 ). Furthermore, as the solute adsorpted on the membrane surface increased along the experiment, 
the hydraulic resistance of the solute adsorpted $\left(\mathrm{R}_{\mathrm{a}}\right)$ also increased, thus causing an additional reduction of the driving force.

Permeate flux in Figure 11 shows a pronounced decrease during the first few minutes of the experiment due to the fast appearance of the polarization layer. Later, the more regular and slower increase of $\mathrm{C}_{\mathrm{m}}$ causes a lesser decrease of the permeate flux. In this same Figure, it can be seen that the higher the feed concentration, the higher the reduction of the permeate flux with respect to pure water flux $\left(\mathrm{J}_{\mathrm{w}}\right)$. The initial concentration had a great influence on the permeate flux. However, the evolution of permeate flux with time was very similar from one experiment to another: after the initial reduction, the slope of the curves was very small and similar in all the experiments.

\subsection{Application of a mathematical model to the experimental data}

In a previous paper [24], in order to model the concentration profiles experimentally obtained, the convection-diffusion equation (1) in a dead-end reverse osmosis process, combined with the boundary conditions (equations (2), (3) and (4)) and the osmotic pressure model (6) were used. In that paper [24], concentrations on the membrane surface $\left(C_{m}\right)$ were very high because all the solute which was transported by convection to the boundary layer was retained there in solution. As in RO there is no formation of gel layer or appreciable adsorption, in equation (6) only the hydraulic resistance of the membrane $\left(\mathrm{R}_{\mathrm{m}}\right)$ appeared.

However, according to the experimental results obtained in this paper, when PEG-10000 is ultrafiltered there is an adsorption or deposition of solute on the membrane surface. Therefore, the simulation of the experiments with the mathematical model previously explained must be done using equations (5) and (8) instead of equations (4) and (6), respectively. When PEG was ultrafiltered, concentrations at the surface of the membrane $\left(\mathrm{C}_{\mathrm{m}}\right)$ were lower than those for RO because a very important part of the solute transported by convection to the membrane was 
adsorpted on the surface of the membrane $\left(\mathrm{S}_{\mathrm{a}}, \mathrm{kg} / \mathrm{m}^{2}\right)$ thus the solute dissolved in the boundary layer was not increased. On the other hand, the layer of solute adsorpted represents an additional hydraulic resistance $\left(R_{a}\right)$ included in equation (8). In equation (5), the term $d S_{a} / d t$ refers to a variation in the solute accumulated with time throughout the ultrafiltration process.

Experimental observations described in section 4.1, as well as discussion in section 4.2, clearly show that an accumulation of solute on the filter, that includes concentration polarization and reversible membrane fouling (formation of an adsorption layer or deposit), occurs during PEG-10000 ultrafiltration. Fouling mechanism in UF of colloidal suspensions has been studied by Bacchin et al. [10, 34], Bachin and Aimar [35] and Espinasse et al. [36]. Studying the UF of macromolecular solutions they found that the higher concentration and transmembrane pressure, the greater the forces of interaction between the macromolecules and with the surface of the membrane.

In order to study if the adsorption of PEG-10000 on a cellulose acetate membrane was affected by pressure, several experiments were carried out. In these experiments, the support of the membrane in the UF module was substituted by a no-permeable support, in order to avoid the filtration process. When the UF module was filled PEG-10000 solution, no interference fringes were observed (which means solute concentration remained the same and therefore, no adsorption of solute on the membrane had taken place). However, when pressure was applied $(\Delta \mathrm{P}=1 \mathrm{bar})$, a great number of interference fringes appeared near the surface of the membrane (it should be noted that, due to the use of a no-permeable support, the PEG-10000 solution was no flowing through the membrane). These fringes appeared as a consequence of a decrease of the solute concentration near the membrane due to solute adsorption.

In a UF experiment, as those described in section 4.1, the convective flux provides solute to the membrane, thus increasing concentration; furthermore, the solution is pressurized. Both causes (concentration and pressure) provide suitable conditions to encourage the interaction of the macromolecules between them and with the surface of the membrane, appearing the fouling 
phenomenon. This forced adsorption caused by the convective flux and by pressure is reversible so, when the pressure and the convective flux cease, the solute responsible of fouling disappears.

The amount of solute deposited per unit of area during the time (t) that lasts the UF process $\left(S_{\mathrm{a}}\right)$, has been obtained with the empirical equation:

$$
S_{a}=\frac{A \cdot C^{\prime}}{\left(1-C^{\prime}\right) \cdot\left(1+B \cdot C^{\prime}\right)}
$$

C' has been conventionally defined as:

$$
\mathrm{C}^{\prime}=\frac{\mathrm{C}_{\mathrm{m}}-\mathrm{C}_{0}}{\mathrm{C}_{\mathrm{m}}}
$$

Parameters $\mathrm{A}$ and $\mathrm{B}$ in equation (14) were calculated by using the experimental mass balances, that allowed the value of $S_{a}$ to be estimated as the difference between the amount of solute entering the ultrafiltration cell $\left(\int_{0}^{\mathrm{t}}\left(\mathrm{JC}_{\mathrm{o}}\right) \mathrm{dt}\right)$ and the amount of solute accumulated in the boundary layer $\left(\int_{0}^{\delta} \mathrm{C} \cdot \mathrm{dy}\right)$. The resulting values of the parameters were: $\mathrm{A}=0.1$ and $\mathrm{B}=10$.

The adsorption resistance used in equation (8) is assumed proportional to the amount of solute adsorpted

$$
\mathrm{R}_{\mathrm{a}}=\mathrm{K} \cdot \mathrm{S}_{\mathrm{a}}
$$

To simulate the experiments, the mathematical model previously explained was used together with the new equations presented in this section. Equations (1), (8) and (14) were used to calculate the permeate flux, the concentration of solute in the boundary layer and the concentration of solute adsorbed on the membrane. A numerical method was used to simultaneously solve these equations with the boundary conditions (2), (3) and (5). Some data introduced in the model were: feed concentration of the solution $\left(\mathrm{C}_{\mathrm{o}}\right)$, pressure applied $(\Delta \mathrm{P})$, diffusion coefficient (D) and pure water permeate flux $\left(\mathrm{J}_{\mathrm{w}}\right)$. Moreover, in the boundary condition (3), the thickness of the boundary layer must be introduced. In order to obtain this, an 
unattainable great value of $\delta$ was used. After running the calculation program it was checked that the value of $\delta$ calculated was lower than the value of $\delta$ assumed.

The constant of the adsorption resistance (Equation (16)) was an adjustable parameter. It was found that in the range of concentrations used this was dependent on the feed concentration, according to expression $\mathrm{K}=\mathrm{C}_{\mathrm{o}} \times 10^{7}$.

A reasonable agreement between the experimental and calculated concentration profiles was obtained (Figure 8), the greater the time and the initial concentration, the better the agreement. Experimental and calculated permeate fluxes were also very similar (Figure 11). Both results (concentration and permeate flux profiles) indicate that the combination of a mechanism of convection-diffusion with the osmotic pressure theory and an empirical equation with a hydraulic resistance due to the adsorption could be quite an adequate model to describe PEG ultrafiltration processes operating in unstirred batch conditions, in the range of the experimental conditions studied. Parameters A, B and K are the same for the 4 sets of experiments with different feed concentration. It is evident that simulations would have fitted better if adjustable parameters had been calculated for each concentration.

4.5. Comparing these results with those obtained in previous papers about the visualization of the UF polarized layer by Holographic Interferometry

In a previous paper [22], ultrafiltration of BSA protein using a polyethersulfone (PES) membrane was studied. As has been pointed out in the Experimental section, the module had an orientation (vertical) different from that used in this work (horizontal). On the other hand, it is known that the phenomenon of protein adsorption between BSA and the PES membranes is stronger than that between PEG and cellulose acetate membranes. These differences may explain that the observed number of interference fringes in UF of BSA (up to 8 fringes) was smaller than in UF of PEG (up to 31 fringes). A lesser number of fringes means flatter profiles and therefore, a lower amount of solute in solution in the polarization layer. The most consistent explanation is 
to assume that part of the BSA solute rejected by the PES membrane is not in solution, but undergo a process of coagulation, aggregation, precipitation, and forms the so-called gel or filtercake layer on the surface of the membrane. This filter-cake could be visualized when the pump was switched off, because releasing the pressure caused the cake to relax, allowing to observe, at certain moments, gelatinous mass of small drops trickle down the vertical surface of the membrane.

In another previous work [23], UF of PEG 2000 using a membrane of cellulose acetate was studied. The behaviour was expected to be different from the BSA with the PES membrane. Thus, although there was a reversible adsorption of PEG on the membrane, the concentration profiles were more important than those that appeared when ultrafiltering BSA. Comparing the UF of PEG 2000 [23] with the UF of PEG 10000 developed in this paper, the substance is the same (PEG) although the molecular weight of the solute is different; however, the main difference is the position of the module, vertical in the previous paper [23] and horizontal in this research.

In an excellent experimental study on the effects of natural convection instability on membrane performance in dead-end and cross-flow UF, Youm et al. [30] presented the buoyancy phenomenon in a very clear way. In membrane separations, as a consequence of the variation of solute concentration across the concentration polarization layer, a density variation occurs so that the solution density at the membrane surface is higher than that in the bulk solution. By changing the gravitational orientation of the module, a density inversion is obtained, which may lead to an unstable fluid behaviour causing natural convection or buoyancy flow in the vicinity of the membrane surface. In the paper [30], three different orientations were studied: zero gravity in the flow direction $\left(90^{\circ}\right)$, gravity acting in the same direction as the flow direction $\left(0^{\circ}\right)$, and gravity acting in the opposite direction to the flow (the most gravitationally unstable orientation) $\left(180^{\circ}\right)$. Studying dead-end UF of BSA and Dextran, they found that the permeate flow for the $0^{\circ}$ orientation (horizontal, upward facing surface membrane) was the lowest, whereas the maximum 
flow was obtained for the $180^{\circ}$ orientation (horizontal membrane surface facing upward); for $90^{\circ}$ (vertical), the flow was in between the other two orientations.

In paper [23], with the module placed in the $90^{\circ}$ orientation, the number of fringes was lower than in this paper. Moreover, the polarization layer was thinner $(\delta<0.2 \mathrm{~mm})$ in the UF of PEG 2000 [23] than in the UF of PEG $10000(\delta>0.5 \mathrm{~mm})$ and thus the permeate flow was higher with PEG 2000.

On the other hand, the absence of instabilities in the polarization layer in this paper allows a theoretical interpretation of the experimental results using a convection-diffusion model with an adsorption hypothesis. In the case of PEG $2000 \mathrm{UF}$, the theoretical interpretation was more complicated and was not included because of the difficulties in modelling the gravitational instabilities. In this sense, the present work, with better-designed experiments than on the previous work [23] and without the disturbing gravitational effects, brings the possibility of understanding the mechanism of built-up of the polarization layer during the UF of PEG solutions.

\section{Conclusions}

Real-time holographic interferometry technique has proved to be a useful tool to visualize the evolution of the polarization layer during the ultrafiltration of PEG-10000. Three sets of deadend ultrafiltration experiments have been carried out varying the feed concentration of PEG10000 from 5 to $12.5 \mathrm{~kg} / \mathrm{m}^{3}$. All the experiments have been carried out at a constant pressure of 1 bar. In all the experiments it has been possible to follow the appearance, evolution and disappearance of the polarization layer. Experimental results have also shown evidence of the existence of a reversible adsorption process on the membrane surface.

Concentration profiles in the polarized layer have been determined. They show that the concentration at the membrane surface $\left(C_{m}\right)$ as well as the thickness of the boundary layer $(\delta)$ 
were continuously increasing. Thus, the process was far enough from the stationary state along the experiment (1 hour).

Permeate flux was also determined. This variable undergoes a reduction with time due to the continuous growth of the polarization layer. This reduction is faster during the first few minutes of the experiments and becomes slower as time goes by.

The appearance of additional interference fringes when the driving force ceased confirms the existence of an amount of solute adsorpted on the membrane surface that returns to the bulk solution when the pressure ceased. The existence of solute adsorpted is also corroborated with the mass imbalance between the solute entering the ultrafiltration cell and the solute accumulated in the boundary layer. This adsorption process is reversible since the solute adsorpted on the membrane returns to solution.

A mathematical model has been proposed to simulate the dead-end UF process, by adding an empirical equation to the adsorption process. This model is a combination of the convectiondiffusion mechanism, the osmotic pressure theory and a hydraulic resistance due to the adsorption. It has been validated, under the experimental conditions used, by a reasonable agreement between experimental and calculated results (concentration profiles and permeate flux).

\section{Acknowledgements}

This research has been sponsored by the Plan Nacional de I+D+I CTQ2006-14904 (Ministerio de Educación y Cultura) and University of Alicante; Grupo Transferencia de materiaInterferometría holográfica (VIGROB-128). 


\section{References}

[1] G.B. Van den Berg, C.A. Smolders, Flux decline in ultrafiltration processes, Desalination 77 (1990) 101-133.

[2] S.S. Sablani, M.F.A. Goosen, R. Al-Belushi, M. Wilf, Concentration polarization in ultrafiltration and reverse osmosis: a critical review, Desalination 141 (2001) 269-289.

[3] R. Ghosh, Z. Cui, Analysis of protein transport and polarization through membranes using pulsed sample injection technique, J. Membr. Sci. 175 (2000) 75-84.

[4] T.H. Chong, F.S. Wong, A.G. Fane, Enhanced concentration polarization by unstirred fouling layers in reverse osmosis: Detection by sodium chloride tracer response technique, J. Membr. Sci.287 (2007) 198-210.

[5] E. Lyster, Y. Cohen, Numerical study of concentration polarization in a rectangular reverse osmosis membrane channel: Permeate flux variation and hydrodynamic end effects, J. Membr. Sci. 303 (2007) 140-153.

[6] C. Bhattacharjee, S. Datta, Analysis of polarized layer resistance during ultrafiltration of PEG-6000: an approach based on filtration theory, Sep. Purif. Technol. 33 (2003) 115-126.

[7] M. Cinta Vincent Vela, S. Álvarez Blanco, J. Lora García, E. Bergantiños Rodríguez, Analysis of membrane pore blocking models applied to the ultrafiltration of PEG, Sep. Purif. Technol. 62 (2008) 489-498.

[8] J.P.F. De Bruijn, F.N. Salazar, R. Bórquez, Membrane blocking in ultrafiltration. A new approach to fouling, Food Bioprod. Process. 83 (C3) (2005) 211-219.

[9] R. Ghosh, D.M. Kanani, A constant flux based mathematical model for predicting permeate flux decline in constant pressure protein ultrafiltration, J. Membr. Sci. 290 (2007) 207215. 
[10] P. Bacchin, D. Si-Hassen, V. Starov, M.J. Clifton, P. Aimar, A unifying model for concentration polarization, gel-layer formation and particle deposition in crossflow membrane filtration of colloidal suspensions, Chem. Eng. Sci. 57 (2002) 77-91.

[11] E. Iritani, Y. Mukai, E. Hagihara, Measurements and evaluation of concentration distributions in filter cake formed in dead-end ultrafilltration of protein solutions, Chem. Eng. Sci. 57 (2002) 53-62.

[12] N.V. Churaev, R.G. Holdich, P.P. Prokopovich, V.M. Starov, S.L. Vasin, Reversible adsorption inside pores of ultrafiltration membranes, J. Colloid Interface Sci. 288 (2005) 205212.

[13] S.K. Karode, Unsteady state flux response: a method to determine the nature of the solute and gel layer in membrane filtration, J. Membr. Sci. 188 (2001) 9-20.

[14] S. Nicolas, I. Boulanouar, B. Balou, Unstirred dead-end ultrafiltration: a method to determine diffusion coefficient or osmotic pressure for non-charged macromolecular solutions, J. Membr. Sci. 103 (1995) 19-30.

[15] C. Bhattacharjee, A numerical simulation for the prediction of flux and rejection during ultrafiltration in unstirred batch cell using variable diffusivity concept, Sep. Purif. Technol. 24 (2001) 13-22.

[16] V. Chen, H. Li, A.G. Fane, Non-invasive observation of synthetic membrane processesa review of methods, J. Membr. Sci. 241 (2004) 23-44.

[17] D. Airey, S. Yao, J. Wu, V. Chen, A.G. Fane, J.M. Pope, An investigation of concentration polarization phenomena in membrane filtration of colloidal silica suspensions by NMR micro-imaging, J. Membr. Sci.145 (1998) 145-158.

[18] A.R. Johnson, Experimental investigation of polarization effects in reverse osmosis, AIChE J. 20 (1974) 966-974. 
[19] M. Clifton, V. Sanchez, Holographic interferometry applied to the measurement of boundary layers in electrodialysis and ultrafiltration, SPIE 211, Opt. Photonics Appl. Med. (1979) 111- 115.

[20] D. Mahlab, N.B. Yosef, G. Belfort, Concentration polarization profile for dissolved species in unstirred batch hyperfiltration (reverse osmosis) - II transient case, Desalination 24 (1978) 297- 303.

[21] D. Mahlab, N.B. Yosef, G. Belfort, Interferometric measurement of concentration polarization profile for dissolved species in unstirred batch hyperfiltration (reverse osmosis), Chem. Eng Commun 6 (1980) 225-243

[22] M.J. Fernández Torres, F. Ruiz-Beviá, J. Fernández-Sempere, M. López-Leiva, Visualization of the UF Polarizad Layer by Holographic Interferometry, AIChE J. 44 (1998) $1765-1776$.

[23] J. Fernández-Sempere, F. Ruiz-Beviá, R. Salcedo-Díaz, Measurements by holographic interferometry of concentration profiles in dead-end ultrafiltration of polyethylene glycol solutions, J. Membr. Sci. 229 (2004) 187-197.

[24] F. Ruiz-Beviá, J. Fernández-Sempere, R. Salcedo-Díaz, P. García-Algado, Measurements of concentration profiles by holographic interferometry and modeling in unstirred batch reverse osmosis, Ind. Eng. Chem. Res. 45 (2006) 7219-7231.

[25] F. Ruiz-Beviá, J. Fernández-Sempere, R. Salcedo-Díaz, P. García-Algado, Buoyancy effects in dead-end reverse osmosis: visualization by holographic interferometry, Ind. Eng. Chem. Res. 46 (2007) 1794-1802.

[26] F. Ruiz-Beviá, J. Fernández-Sempere, R. Salcedo-Díaz, P. García-Algado, Diffusion studies in polarized reverse osmosis processes by holographic interferometry, Opt. Lasers Eng. 46 (2008) 877-887.

[27] F. Ruiz-Beviá, J. Fernández-Sempere, J. Colom-Valiente, Diffusivity Measurement in Calcium Alginate Gel by Holographic Interferometry, AIChE J. 35(11) (1989) 1895-1898. 
[28] J. Fernández-Sempere, F. Ruiz-Beviá, J. Colom-Valiente, F. Mas-Pérez, Determination of Diffusion Coefficients of Glycols, J. Chem. Eng. Data 41 (1996) 47-48.

[29] J.D. Nikolova, M.A. Islam, Contribution of adsorbed layer resistance to the flux-decline in an ultrafiltration process, J. Membr. Sci. 146 (1998) 105-111.

[30] K.H. Youm, A.G. Fane, D.E. Wiley, Effects of natural convection instability on membrane performance in dead-end and cross-flow ultrafiltration, J. Membr. Sci. 116 (1996) 229-241.

[31] J. Fernández-Sempere, F. Ruiz-Beviá, R. Salcedo-Díaz, P. García-Algado, Equipo experimental para visualizar la formación de la capa de polarización durante el proceso de ósmosis inversa, Ing. Quim. 438 (2006) 147-154.

[32] A. Vergara, L. Paduano, V. Vitagliano, R. Sartorio, Mutual diffusion in aqueous solution of poly(ethyleneglycol) samples. Some comments on the effect of chain length and polydispersity, Phys. Chem. Chem. Phys. 1 (1999) 5377-5383.

[33] N.P. Money, Osmotic pressure of aqueous polyethylene glycols, Plant Physiol. 91 (1989) 766-769.

[34] P. Bachin, P. Aimar R. W. Feld, Critical and sustainable fluxes: Theory, experiments and applications, J. Membr. Sci. 281 (2006) 42-69.

[35] P. Bachin, P. Aimar, Critical fouling conditions induced by colloidal surface interactions: from causes to consequences, Desalination 175 (2005) 21-27.

[36] B. Espinasse, P. Bachin, P. Aimar, Filtration method characterizing the reversibility of colloidal fouling layers at a membrane surface: Analysis through flux and osmotic pressure, J. Membr. Sci. 320 (2008) 483-490. 
Table 1

\begin{tabular}{|c|c|c|c|c|c|}
\hline \multirow{3}{*}{$\begin{array}{l}\text { Interferogram } \\
\text { Fringe Order No. }\end{array}$} & \multicolumn{5}{|c|}{ Experiment $I: C_{o}=5 \mathrm{~kg} / \mathrm{m}^{3}$} \\
\hline & \multicolumn{4}{|l|}{$y(\mathrm{~mm})$} & \multirow{2}{*}{$\begin{array}{l}\mathrm{C} \\
\left(\mathrm{kg} / \mathrm{m}^{3}\right)\end{array}$} \\
\hline & at $15 \mathrm{~min}$ & at $30 \mathrm{~min}$ & at $45 \mathrm{~min}$ & at $60 \mathrm{~min}$ & \\
\hline 1 & 0.15 & 0.35 & 0.51 & 0.66 & 5.47 \\
\hline 2 & 0.09 & 0.25 & 0.38 & 0.49 & 5.95 \\
\hline 3 & 0.04 & 0.19 & 0.32 & 0.42 & 6.43 \\
\hline 4 & & 0.14 & 0.26 & 0.36 & 6.91 \\
\hline 5 & & 0.10 & 0.23 & 0.33 & 7.39 \\
\hline 6 & & 0.07 & 0.19 & 0.29 & 7.87 \\
\hline 7 & & 0.03 & 0.15 & 0.25 & 8.35 \\
\hline 8 & & & 0.12 & 0.23 & 8.83 \\
\hline 9 & & & 0.10 & 0.19 & 9.30 \\
\hline 10 & & & 0.07 & 0.17 & 9.78 \\
\hline 11 & & & 0.04 & 0.14 & 10.26 \\
\hline 12 & & & 0.01 & 0.11 & 10.74 \\
\hline 13 & & & & 0.09 & 11.22 \\
\hline 14 & & & & 0.06 & 11.70 \\
\hline 15 & & & & 0.04 & 12.18 \\
\hline 16 & & & & 0.02 & 12.66 \\
\hline
\end{tabular}


Table 2

\begin{tabular}{|c|c|c|c|c|c|}
\hline \multirow{3}{*}{$\begin{array}{l}\text { Interferogram } \\
\text { Fringe Order No. }\end{array}$} & \multicolumn{5}{|c|}{ Experiment II : $C_{o}=7.5 \mathrm{~kg} / \mathrm{m}^{3}$} \\
\hline & \multicolumn{4}{|l|}{$y(\mathrm{~mm})$} & \multirow{2}{*}{$\begin{array}{l}\mathrm{C} \\
\left(\mathrm{kg} / \mathrm{m}^{3}\right)\end{array}$} \\
\hline & at $15 \mathrm{~min}$ & at $30 \mathrm{~min}$ & at $45 \mathrm{~min}$ & at $60 \mathrm{~min}$ & \\
\hline 1 & 0.23 & 0.41 & 0.58 & 0.81 & 7.98 \\
\hline 2 & 0.14 & 0.33 & 0.44 & 0.58 & 8.46 \\
\hline 3 & 0.10 & 0.26 & 0.38 & 0.50 & 8.94 \\
\hline 4 & 0.05 & 0.21 & 0.34 & 0.45 & 9.42 \\
\hline 5 & 0.01 & 0.17 & 0.30 & 0.41 & 9.89 \\
\hline 6 & & 0.14 & 0.27 & 0.38 & 10.37 \\
\hline 7 & & 0.11 & 0.24 & 0.34 & 10.85 \\
\hline 8 & & 0.08 & 0.20 & 0.31 & 11.33 \\
\hline 9 & & 0.04 & 0.17 & 0.28 & 11.81 \\
\hline 10 & & 0.01 & 0.15 & 0.25 & 12.29 \\
\hline 11 & & & 0.12 & 0.22 & 12.77 \\
\hline 12 & & & 0.10 & 0.20 & 13.25 \\
\hline 13 & & & 0.07 & 0.17 & 13.72 \\
\hline 14 & & & 0.04 & 0.15 & 14.20 \\
\hline 15 & & & 0.02 & 0.13 & 14.68 \\
\hline 16 & & & & 0.10 & 15.16 \\
\hline 17 & & & & 0.08 & 15.64 \\
\hline 18 & & & & 0.06 & 16.12 \\
\hline 19 & & & & 0.03 & 16.60 \\
\hline 20 & & & & 0.01 & 17.08 \\
\hline
\end{tabular}


Table 3

Experiment III : $C_{o}=10 \mathrm{~kg} / \mathrm{m}^{3}$

\begin{tabular}{lll}
\hline Interferogram $y(\mathrm{~mm})$ & $\mathrm{C}$
\end{tabular}

Fringe Order No. at $15 \mathrm{~min}$ at $30 \mathrm{~min}$ at $45 \mathrm{~min}$ at $60 \mathrm{~min}\left(\mathrm{~kg} / \mathrm{m}^{3}\right)$

\begin{tabular}{|c|c|c|c|c|c|}
\hline 1 & 0.32 & 0.71 & 0.78 & 0.84 & 10.48 \\
\hline 2 & 0.24 & 0.51 & 0.62 & 0.73 & 10.96 \\
\hline 3 & 0.18 & 0.43 & 0.54 & 0.66 & 11.44 \\
\hline 4 & 0.14 & 0.37 & 0.49 & 0.60 & 11.92 \\
\hline 5 & 0.10 & 0.33 & 0.45 & 0.56 & 12.39 \\
\hline 6 & 0.06 & 0.29 & 0.41 & 0.52 & 12.87 \\
\hline 7 & 0.03 & 0.26 & 0.38 & 0.48 & 13.35 \\
\hline 8 & & 0.22 & 0.35 & 0.45 & 13.83 \\
\hline 9 & & 0.20 & 0.32 & 0.43 & 14.31 \\
\hline 10 & & 0.16 & 0.29 & 0.40 & 14.79 \\
\hline 11 & & 0.14 & 0.26 & 0.37 & 15.27 \\
\hline 12 & & 0.11 & 0.24 & 0.35 & 15.75 \\
\hline 13 & & 0.09 & 0.21 & 0.32 & 16.22 \\
\hline 14 & & 0.06 & 0.19 & 0.30 & 16.70 \\
\hline 15 & & 0.04 & 0.16 & 0.28 & 17.18 \\
\hline 16 & & 0.01 & 0.14 & 0.25 & 17.66 \\
\hline 17 & & & 0.12 & 0.23 & 18.14 \\
\hline 18 & & & 0.10 & 0.21 & 18.62 \\
\hline 19 & & & 0.07 & 0.19 & 19.10 \\
\hline 20 & & & 0.05 & 0.17 & 19.58 \\
\hline 21 & & & 0.03 & 0.14 & 20.05 \\
\hline 22 & & & 0.01 & 0.13 & 20.53 \\
\hline 23 & & & & 0.11 & 21.01 \\
\hline 24 & & & & 0.08 & 21.49 \\
\hline & & & & 0.06 & 21.97 \\
\hline
\end{tabular}


Table 4

Experiment $\mathrm{IV}: \mathrm{C}_{o}=12.5 \mathrm{~kg} / \mathrm{m}^{3}$

\begin{tabular}{lll}
\hline Interferogram $y(\mathrm{~mm})$ & $\mathrm{C}$
\end{tabular}

Fringe Order No. at $15 \mathrm{~min}$ at $30 \mathrm{~min}$ at $45 \mathrm{~min}$ at $60 \mathrm{~min} \quad\left(\mathrm{~kg} / \mathrm{m}^{3}\right)$

\begin{tabular}{|c|c|c|c|c|c|}
\hline 1 & 0.33 & 0.52 & 0.65 & 0.81 & 12.98 \\
\hline 2 & 0.25 & 0.44 & 0.58 & 0.73 & 13.46 \\
\hline 3 & 0.20 & 0.39 & 0.53 & 0.67 & 13.94 \\
\hline 4 & 0.15 & 0.35 & 0.49 & 0.63 & 14.42 \\
\hline 5 & 0.11 & 0.32 & 0.45 & 0.60 & 14.89 \\
\hline 6 & 0.08 & 0.28 & 0.42 & 0.56 & 15.37 \\
\hline 7 & 0.04 & 0.25 & 0.39 & 0.53 & 15.85 \\
\hline 8 & 0.01 & 0.22 & 0.36 & 0.50 & 16.33 \\
\hline 9 & & 0.20 & 0.34 & 0.47 & 16.81 \\
\hline 10 & & 0.17 & 0.31 & 0.45 & 17.29 \\
\hline 11 & & 0.15 & 0.29 & 0.42 & 17.77 \\
\hline 12 & & 0.12 & 0.26 & 0.40 & 18.25 \\
\hline 13 & & 0.10 & 0.24 & 0.37 & 18.72 \\
\hline 14 & & 0.07 & 0.22 & 0.35 & 19.20 \\
\hline 15 & & 0.05 & 0.20 & 0.33 & 19.68 \\
\hline 16 & & 0.02 & 0.17 & 0.31 & 20.16 \\
\hline 17 & & & 0.15 & 0.29 & 20.64 \\
\hline 18 & & & 0.13 & 0.27 & 21.12 \\
\hline 19 & & & 0.11 & 0.25 & 21.60 \\
\hline 20 & & & 0.09 & 0.23 & 22.08 \\
\hline 21 & & & 0.07 & 0.21 & 22.55 \\
\hline 2 & & & 0.05 & 0.19 & 23.03 \\
\hline 23 & & & 0.03 & 0.16 & 23.51 \\
\hline 2 & & & & 0.15 & 23.99 \\
\hline & & & & 0.13 & 24.47 \\
\hline
\end{tabular}


26

27

28

29

30

31
0.11

24.95

0.10

25.43

0.07

25.91

0.05

26.39

0.04

26.86

0.02

27.34 
Table 5

\begin{tabular}{|c|c|c|c|c|c|c|c|c|c|c|}
\hline & & \multicolumn{5}{|c|}{$\Delta \mathrm{P}=1$ bar } & \multicolumn{4}{|c|}{$\Delta \mathrm{P}=0$ bar } \\
\hline \multicolumn{2}{|l|}{ Time (min) } & 5 & 15 & 30 & 45 & 60 & 25 & 35 & 50 & 70 \\
\hline \multirow{2}{*}{$\begin{array}{c}\mathrm{C}_{\mathrm{o}}= \\
7.5 \mathrm{~kg} / \mathrm{m}^{3}\end{array}$} & $\begin{array}{l}\text { Solute entrance, } \\
\int \mathrm{J} \cdot \mathrm{C}_{\mathrm{o}} \mathrm{dt}\left(\mathrm{kg} / \mathrm{m}^{2}\right)\end{array}$ & 0.00295 & 0.00733 & 0.01269 & 0.01686 & 0.02046 & & & & \\
\hline & $\begin{array}{l}\text { Accumulated } \\
\text { solute, } \quad \int \mathrm{C} \cdot \mathrm{dx} \\
\left(\mathrm{kg} / \mathrm{m}^{2}\right)\end{array}$ & 0.00006 & 0.00040 & 0.00103 & 0.00185 & 0.00288 & 0.01377 & 0.01435 & 0.01628 & 0.01651 \\
\hline \multirow{2}{*}{$\begin{array}{l}\mathrm{C}_{\mathrm{o}}= \\
12.5 \\
\mathrm{~kg} / \mathrm{m}^{3}\end{array}$} & $\begin{array}{l}\text { Solute entrance, } \\
\int \mathrm{J} \cdot \mathrm{C}_{\mathrm{o}} \mathrm{dt}\left(\mathrm{kg} / \mathrm{m}^{2}\right)\end{array}$ & 0.00374 & 0.00956 & 0.01615 & 0.02092 & 0.02525 & & & & \\
\hline & $\begin{array}{l}\text { Accumulated } \\
\text { solute, } \quad \int \mathrm{C} \cdot \mathrm{dx} \\
\left(\mathrm{kg} / \mathrm{m}^{2}\right)\end{array}$ & 0.00018 & 0.00065 & 0.00189 & 0.00379 & 0.00517 & 0.01568 & 0.01894 & 0.01940 & 0.02014 \\
\hline
\end{tabular}




\section{Figure captions}

Figure 1. Boundary conditions employed for the mathematical model.

Figure 2. Holographic interferometry system.

Figure 3. Ultrafiltration system: (1) nitrogen cylinder; (2) pressure-control valve; (3a and b) precision regulation valves; (4) pressure gauges; (5) damper, (6) UF module; (7) inlet and outlet valves; (8) feed and water tanks; (9) pump; (10) permeate collector vessel and balance; (11) computer.

Figure 4. Interferograms belonging to Experiment of $C_{o}=7.5 \mathrm{~kg} / \mathrm{m}^{3}$ at $15,30,45$, and 60 minutes. The membrane position in each interferogram is indicated by means of an additional longer line that extends on each side of the interferogram.

Figure 5. Interferograms belonging to Experiment of $C_{o}=12.5 \mathrm{~kg} / \mathrm{m}^{3}$ at $15,30,45$, and 60 minutes.

Figure 6. Interferograms belonging to Experiment of $C_{o}=7.5 \mathrm{~kg} / \mathrm{m}^{3}$ at 0 (just before the pressure ceases), 5, 12, 25, 35 and 50 minutes after the pressure ceased. Magnification is different in each interferogram.

Figure 7. Interferograms belonging to Experiment of $C_{o}=12.5 \mathrm{~kg} / \mathrm{m}^{3}$ at 0 (just before the pressure ceases), 5, 12, 25, 35 and 50 minutes after the pressure ceased. Magnification is different in each interferogram.

Figure 8. Experimental concentration profiles at different times $(\diamond 15 \mathrm{~min}, * 30 \mathrm{~min}, \triangle 45$ min, $\square 60 \mathrm{~min},-$ model calculation). (a) $\mathrm{C}_{\mathrm{o}}=5 \mathrm{~kg} / \mathrm{m}^{3}$; (b) $\mathrm{C}_{\mathrm{o}}=7.5 \mathrm{~kg} / \mathrm{m}^{3}$; (c) $\mathrm{C}_{\mathrm{o}}=10$ $\mathrm{kg} / \mathrm{m}^{3} ;$ (d) $\mathrm{C}_{\mathrm{o}}=12.5 \mathrm{~kg} / \mathrm{m}^{3}$.

Figure 9. Control-volume for the mass balance. 
Figure 10. Experimental concentration profiles at different times after the pressure ceased (0min, $\diamond 5 \mathrm{~min}, \square 12 \mathrm{~min}, \triangle 25 \mathrm{~min}, * 50 \mathrm{~min}, \circ 70 \mathrm{~min}$ ). (a) $\mathrm{C}_{\mathrm{o}}=5 \mathrm{~kg} / \mathrm{m}^{3}$; (b) $\mathrm{C}_{\mathrm{o}}=7.5$ $\mathrm{kg} / \mathrm{m}^{3}$; (c) $\mathrm{C}_{\mathrm{o}}=10 \mathrm{~kg} / \mathrm{m}^{3} ;$ (d) $\mathrm{C}_{\mathrm{o}}=12.5 \mathrm{~kg} / \mathrm{m}^{3}$.

Figure 11. Evolution of the experimental dimensionless flux $\left(\mathrm{J} / \mathrm{J}_{\mathrm{w}}\right)$ for each feed concentration ( $\times 5 \mathrm{~kg} / \mathrm{m}^{3}, \triangle 7.5 \mathrm{~kg} / \mathrm{m}^{3}, \square 10 \mathrm{~kg} / \mathrm{m}^{3}, \bigcirc 12.5 \mathrm{~kg} / \mathrm{m}^{3}$, - calculated). 


\section{TABLES}

Table 1. PEG Concentration profiles when $\mathrm{C}_{\mathrm{o}}=5 \mathrm{~kg} / \mathrm{m}^{3}$

Table 2. PEG Concentration profiles when $\mathrm{C}_{\mathrm{o}}=7.5 \mathrm{~kg} / \mathrm{m}^{3}$

Table 3. PEG Concentration profiles when $\mathrm{C}_{\mathrm{o}}=10 \mathrm{~kg} / \mathrm{m}^{3}$

Table 4. PEG Concentration profiles when $\mathrm{C}_{\mathrm{o}}=12.5 \mathrm{~kg} / \mathrm{m}^{3}$

Table 5. Solute balance in the control-volume (Figure 9) when the UF process takes place $(\Delta \mathrm{P}$ $=1$ bar $)$ and once the pressure has ceased $(\Delta \mathrm{P}=0$ bar $)$ 


\title{
VISUALIZATION AND MODELLING OF THE POLARIZATION LAYER AND A REVERSIBLE ADSORPTION PROCESS IN PEG-10000 DEAD-END ULTRAFILTRATION
}

J. Fernández-Sempere, F. Ruiz-Beviá*, P. García-Algado, R. Salcedo-Díaz.

Departamento de Ingeniería Química. Universidad de Alicante. Apartado 99. E-03080 Alicante (Spain). Fax. +34965903826. Telf. +34965903867. ruiz.bevia@ua.es.

\begin{abstract}
Real-time holographic interferometry has been used to visualize the evolution of the polarization layer during dead-end ultrafiltration of PEG-10000. Several experiments varying the feed concentration of PEG-10000 (5 - 12.5 kg/m $\mathrm{m}^{3}$ ) have been carried out at a constant pressure of 1 bar. In all the experiments it has been possible to follow the appearance, evolution and disappearance of the polarization layer. Experimental results have also shown evidence of the existence of a reversible adsorption process on the membrane surface.

A mathematical model has been proposed for the simulation of the dead-end UF process. This model, based on the convection-diffusion mechanism and the osmotic pressure theory, has been combined with an empirical equation for the adsorption process. The model has been validated, under the experimental conditions used, by a reasonable agreement between experimental and calculated results (concentration profiles and permeate flux).
\end{abstract}

Keywords: Ultrafiltration, holographic interferometry, concentration profiles, adsorption, modelling. 